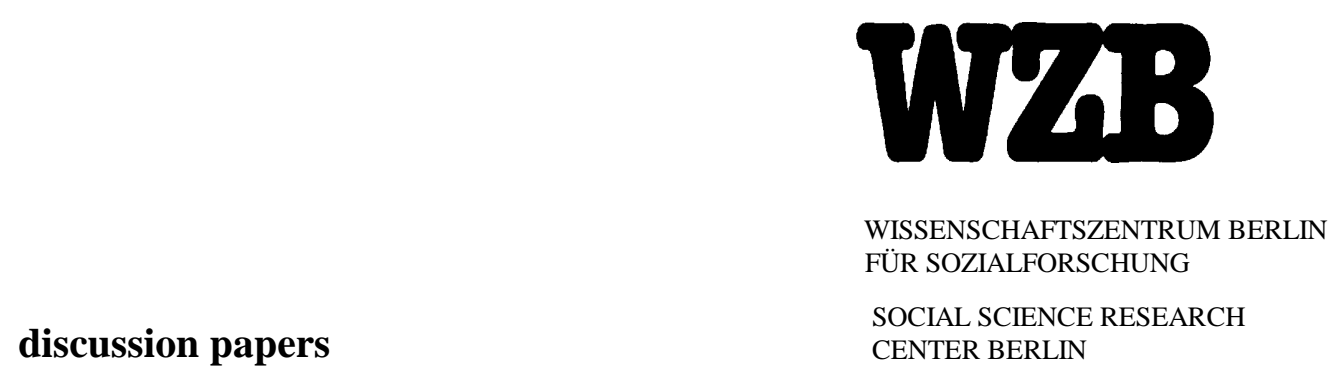

FS IV $01-04$

\title{
Merger and Collusion in Contests
}

Steffen Huck*

Kai A. Konrad**

Wieland Müller***

* Royal Holloway College

** Wissenschaftszentrum Berlin für Sozialforschung

*** Humboldt Universität zu Berlin

January 2001

ISSN Nr. 0722 - 6748

Forschungsschwerpunkt

Markt und politische Ökonomie

Research Area

Markets and Political Economy 


\section{Zitierweise/Citation:}

Steffen Huck, Kai A. Konrad, Wieland Müller, Merger and Collusion in Contests, Discussion Paper FS IV 01-04, Wissenschaftszentrum Berlin, 2001.

Wissenschaftszentrum Berlin für Sozialforschung gGmbH, Reichpietschufer 50, 10785 Berlin, Tel. (030) 25491 - 0 Internet: www.wz-berlin.de 


\section{ABSTRACT}

\section{Merger and Collusion in Contests}

by Steffen Huck, Kai A. Konrad and Wieland Müller

Competition in some product markets takes the form of a contest. If some firms cooperate in such markets, they must decide how to allocate effort on each of their products and whether to reduce the number of their products in the competition. We show how this decision depends on the convexity properties of the contest success function, and we characterize conditions under which cooperation is profitable.

Keywords: Contests, merger, collusion, promotional competition

JEL classification: D44, L11, L13

\section{ZUSAMMENFASSUNG}

\section{Kollusion und Fusion in Contests}

In vielen Gütermärkten erfolgt der Wettbewerb zwischen Unternehmen nicht primär über Preise und Mengen, sondern über Verkaufsanstrengungen. Ein Beispiel hierfür ist der Kampf um Marktanteile und Kunden in Märkten mit hohen Werbeaufwendungen. Wenn Unternehmen in solchen Märkten kooperieren, müssen sie entscheiden, ob sie ihre gesamte Produktpalette beibehalten und ihre Verkaufsanstrengungen auf alle Produkte verteilen (,Kollusion“) oder ob sie die Anzahl ihrer Produkte reduzieren („Fusion“). Wir zeigen, daß diese Entscheidung von den Konvexitätseigenschaften der Funktion abhängt, die den Markterfolg eines Produkts in Abhängigkeit von den Verkaufsanstrengungen für dieses Produkt bzw. für die Konkurrenzprodukte bestimmt, und untersuchen die Bedingungen, in denen Kooperation in Form von „Kollusion“ oder „Fusion“ für die kooperierenden Unternehmen profitabel ist.

Schlüsselbegriffe: Kampf um Marktanteile, Kollusion, Fusion

We thank Helmut Bester for valuable discussion. Konrad gratefully acknowledges financial support by the Norwegian Research Council (Nóring, finans og marked programme). 


\section{Introduction}

Competition in product markets is sometimes well described by a contest, particularly if competition via prices is not feasible. In such markets sellers may contest with each other and spend resources in order to attract customers to buy from them, and not from another seller. The type of effort can differ from one market to another. It may take the form of visits, gifts, persuasive talking, or invitations to conferences in fancy holiday resorts. The latter, for example, is popular in the market for prescription drugs in countries with health care systems. As prescription drugs are covered by health insurance, regardless whether consumers or physicians make the consumption choice, price competition is more or less ruled out. ${ }^{1}$ In other markets sales effort consists of mail and tv-advertising, or, as in the insurance retail business, of visiting and persuasive talking to customers. Again, this becomes particularly pronounced, if price competition is not feasible, which used to be the case in many European insurance markets prior to deregulation on the EU level in $1992 .{ }^{2}$ Prior to deregulation, the regulators protected insurance companies from "ruinous competition" by regulating insurance premiums. Other examples are persuasive advertising, glamorous shop outlets, and huge selections of goods, for instance in the retail market for books where price competition in many countries is hindered by legal vertical price maintenance, or promotional competition in the markets for cigarettes or beverages. ${ }^{3}$

\footnotetext{
${ }^{1}$ Producers use promotional effort in these markets. They send sales representatives and gifts to physicians, trying to persuade them to prescribe their products instead of competing substitutes. For instance, Breyer and Zweifel (1999, p. 366) report that marketing and product information were about 20 percent of revenue through sales in pharmacies in Switzerland in the mid-eighties, almost half of these being marketing expenditure, and argue that this percentage is much higher than that of other industries. Persuasive effort is important in the market for drugs, even for over-the-counter drugs. Sales promotion effort cost cannot be recovered, even if the effort is not successful, turning competition in these markets into a contest. Similarly, Scherer (2000, p. 1303) reports that for over-thecounter drugs, sellers devoted 20.2 percent of their sales receipts to media advertising the highest share among 225 recorded industries.

${ }^{2}$ Rees and Kessner (1999), for instance, survey regulation in the German insurance market prior to 1992. They report evidence for price regulation that led to prices that considerably exceeded cost, leading to a contest in sales effort that was sufficiently strong to make the regulator feel a need for regulating the maximum sales expenditure. The regulator required that agents' commissions were not to exceed 11 percent of premiums, and total marketing expenditure was restricted to no more than 30 percent of premiums.

${ }^{3}$ Other important contest examples are firms competing for a monopoly as in R\&D contests (see, e.g., Bagwell and Staiger 1997), contests for quasi-monopoly due to network externalities (Besen and Farrell 1994), litigation contests for brand names, internet addresses or other exclusive assets that yield quasi-monopoly rents, exporting firms competing for large scale projects as in Konrad (2000), or firms seeking special political favors
} 
Schmalensee (1976) observed and characterized this type of competition in markets with few sellers and differentiated products: "[P]rice competition is relatively rare in such markets. Prices generally change infrequently, and sellers compete, if at all, mainly through product variation and promotional expenditures. It is thus of some interest to attempt to model rigorously markets in which the only competition is of this sort" (Schmalensee 1976, p. 493). With promotional competition, firms spend effort to attain some payoff or "prize": for instance, a large share in a market in which price exceeds marginal cost. Firms win a customer with some probability (or a share in the total market on the aggregate level) as a function of the various efforts of all competing firms. These contests are all-pay auctions. Efforts are made (and sunk) before the customer makes its decision.

In this paper we consider cooperation among a subgroup of $m$ firms in a market with $n(>m)$ firms that is characterized by this type of competition and address two questions. First, we ask what are the factors determining whether the group of cooperating firms will reduce their number of products. For instance, firms often have established brands for close substitutes, and have to decide whether to keep all brands after a merger or to abandon some of them. If they keep all brands, we shall call this collusion. If they reduce the number of brands, we shall call this a merger. Note that these notions do not refer to the institutional form of cooperation, but simply to whether the cooperating firms decide to reduce the number of their brands. Cigarette markets are an example for what we call "collusion" here: the big firms have multiple brands and, when advertising one of their brands, they take into account that they partially cannibalize on their own other brands (Nguyen 1987). The U.S. soft drink industry, in contrast, is an example in which firms seem to concentrate on single brand names. We ask how the type of cooperation is determined by specific characteristics of the contest.

Second, we ask whether cooperation in contests is profitable. The question of profitability of merger or collusion of a subgroup of firms in an industry has received considerable attention for the benchmark case in which sales effort is absent and it has been shown that, somewhat counterintuitively, cooperation can harm cooperators. ${ }^{4}$

Barros and Sørgard (2000) also consider promotional competition, allowing for some form of collusive price setting behavior. They consider only "merger" and study the relationship between advertising and price collusion.

in rent-seeking contests, and the results in this paper could apply qualitatively to these contests as well.

${ }^{4}$ Seminal papers on this benchmark case, considering Cournot competition or Bertrand competition, are Salant, Switzer and Reynolds (1983), Deneckere and Davidson (1985), Gaudet and Salant (1991) and Farrell and Shapiro (1990). 
Their results are sensitive to the particular case of contest success function they use for determining market shares. On a more general level, our results relate to the discussion of cooperative rent-seeking. Dijkstra (1999) considers several structures of cooperation in contests, allowing for matching grants, delegation, and choices of different roles for different members of a cooperating group of rent-seekers. In our paper the group of contestants collapses into one single decision maker that maximizes the group's total payoff. ${ }^{5}$

We proceed as follows. In section 2 we describe our basic model of promotional competition: sales contests. In section 3 we consider the determinants for whether firms merge or collude. In section 4 we consider profitability of merger and collusion, and section 5 concludes.

\section{Contests}

Consider a market with $n$ identical firms. Each firm offers one product (or brand). Suppose that these firms make efforts in a contest for some prize of size $B$. A few examples for this type of competition have been discussed in the introduction. Each firm $i$ chooses contest effort $x_{i} \in[0, \infty)$. These efforts are irreversibly spent by contestants before they know who wins the contest. Contest efforts determine firms' probabilities $q_{i}$ of winning the prize, according to a contest success function

$$
q_{i}\left(x_{1}, \ldots, x_{n}\right)=\frac{\mathrm{p}\left(x_{i}\right)^{a}}{\substack{n=1 \\ j=1}} .
$$

In the context of promotional competition, this parametric form (1) has been used to determine firms' market shares as a function of advertising by Schmalensee (1992, p. 131n.). This contest success function has been suggested by Tullock (1980) in a more general context and is a special case of more general contest success functions but has gained support by an axiomatization in Skaperdas (1996). A further microeconomic underpinning for the specific form of (1) is provided by Fullerton and McAfee (1999). ${ }^{6}$

\footnotetext{
${ }^{5}$ Indeed, if the cooperating firms could write arbitrary contracts on efforts and profit distributions, and if these contracts were credible and observed by the non-cooperating group of contestants, the cooperating group could usually do better than in the merger or collusion outcomes we consider. Different from merger and collusion as discussed here, however, delegation, matching grants, and other such arrangements would typically not be re-negotiation proof at the interim stage.

${ }^{6}$ The function has been widely used to describe interest group competition, lobbying, research and labor market tournaments and other types of competition. Baye, Kovenock and deVries (1998) survey economic applications of contests and Nitzan (1994) surveys the literature on Tullock's contest success function (1).
} 
The coefficient $a$ in (1) is called discriminatory power. It is a measure of how much the contest outcome can be influenced by contest effort, and how much is left to chance. ${ }^{7}$ For instance, if $a \rightarrow 0$, each contestant ends up with the same $q_{i}$, irrespective of contest efforts. If, instead, $a \rightarrow \infty$, (1) approaches a contest success function in which the contestant who makes the highest effort wins the prize. We limit the discriminatory power to $a$ $\in\left[0, \frac{n}{n-1}\right)$ in order to have well-behaved optimization problems with equilibria in pure strategies and first-order conditions characterizing these equilibria. ${ }^{8}$

(We discuss briefly the case $a \rightarrow \infty$ in footnote 10.)

Firms are risk neutral. Their (expected) payoffs are

$$
\pi_{i}=q_{i} B-x_{i} .
$$

Firm $i$ wins $B$ with probability $q_{i}$ and spends contest effort equal to $x_{i}$. The first-order condition for firms maximizing their payoffs and symmetry can be used to calculate the contest equilibrium efforts

$$
x^{*}(n)=\frac{a B(n-1)}{n^{2}} .
$$

The equilibrium share is $1 / n$ for each contestant, yielding the equilibrium payoffs

$$
\pi^{*}(n)=\frac{B}{n}-\frac{a B(n-1)}{n^{2}} .
$$

While firms contest for contracts with individual customers whose decisions can be seen as a random function of sales effort, with many identical customers, $q_{i}$ can also be interpreted as firm $i$ 's market share, and we will make use of this interpretation in what follows.

\section{Cooperation of a subgroup of firms}

Consider a contest of $n$ firms, each firm promoting one product (or 'brand') in a sales contest. Suppose $m$ firms "merge" or "collude". Let $N$ be the set of all

\footnotetext{
${ }^{7}$ If $\mathbf{q}$ is interpreted as a single customer's probability to choose product $\mathbf{i}$, and effort is promotional effort vis-a-vis this customer, micro-data on firms' efforts on each customer for a large set of customers and customers' decisions could be used to estimate a. On the aggregate level, $\mathbf{q}$ could then be interpreted as firm i's market share. Estimating a using aggregate data is more difficult, but a could be inferred from the degree of non-linearity between market shares and sales effort in this case. Thomas (1989) reports some type of non-linearity, for instance, for the U.S. soft drink industry: brands having larger sales exhibit lower ratios of advertising to sales.

${ }^{8}$ For the equilibrium (in mixed strategies) for the case of $\infty>a>n /(n-1)$ see Baye, Kovenock and deVries (1994). For $\mathrm{a} \rightarrow \infty$ see Baye, Kovenock and deVries (1996).
} 
firms and $M$ be the set of firms that cooperate in one of these ways. Denote by $U=N \backslash M$ the set of firms that do not participate in the cooperation. We consider the following contest game. Each non-cooperating firm chooses effort $x_{k}$ in order to maximize its payoff, and the set of cooperating firms chooses a vector $\left(x_{1}, \ldots, x_{m}\right)$ of sales efforts in the $m$ products in order to maximize their joint profits. The total profit of the cooperating firms, $\pi_{M}$, is given by

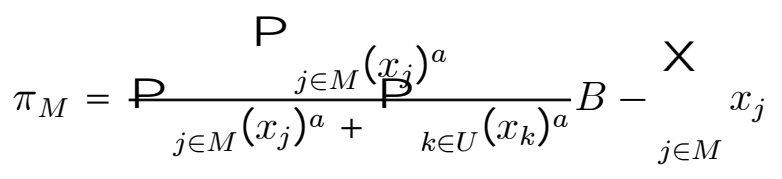

while the profit, $\pi_{u}$ for each non-cooperating firm $u \in U$ is

$$
\pi_{u}=\frac{\left(x_{u}\right)_{\mathrm{P}}^{a}}{{ }_{j \in M}\left(x_{j}\right)^{a}+{ }_{k \in U}\left(x_{k}\right)^{a}} B-x_{u} .
$$

For the equilibrium we obtain

P roposition 1 The cooperating firms allocate the sum of their efforts equally among all products $i \in M$ if $a<1$ and concentrate all effort on one product if $a>1$. If $a=1$, the allocation of efforts between different products $i \in M$ is indeterminate.

Proof. Suppose the $M$-group anticipates the vector of given equilibrium effort choices $\left(x_{u_{1}}, \ldots, x_{u_{n-m}}\right)$ by non-cooperating firms. Whatever this vector is, by (5), if $a=1$, then $\pi_{\mathbf{P} M}$ solely depends on the sum of efforts the cooperating firms exert, i.e., on ${ }_{i \in M} x_{i}$. Accordingly, it does not matter how they allocate their efforts. If $a>1$, the cooperating firms maximize the probability of winning by making use of the increasing returns to scale, i.e., by concentrating all efforts on one product. At the same time the cooperating firms' total costs only depend on the sum of efforts. Hence, $\pi_{M}$ is maximized if indeed all effort is concentrated on one product. Finally, if $a<1$ (i.e., with decreasing returns to scale) it is straightforward to see that the total profit of cooperating firms $\pi_{M}$ is maximized if the total group effort is spread evenly between all product lines.

Note that the result in Proposition 1 generalizes to the broader class of contest success functions with

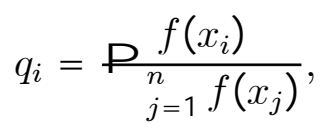


provided that the equilibrium is in pure strategies and characterized by the first-order conditions: Firms "merge" if $f$ is convex, and firms "collude" if $f$ is concave.

An important assumption underlying Proposition 1 is simultaneity: neither the cooperating firms' choice of total equilibrium effort nor the allocation of this amount between different products becomes known to the noncooperating firms before they choose their own efforts. Cooperating firms may sometimes choose to close down a number of products and keep only $h \leq m$ products when they decide to cooperate, and this may be observed by the non-cooperating firms before all firms enter the actual contest game of choosing efforts. Proposition 1 states that in this case cooperating firms would choose to spread effort equally among the remaining $h$ product lines if $a<1$, and to concentrate all effort on one product if $a>1 .^{9}$

\section{Profitability}

Consider now whether cooperation of a subgroup of firms is profitable for this group. From Proposition 1 we know that cooperation essentially leads to a situation in which the set of non-cooperating firms contest with one single firm with one product if $a>1$. If $a<1$, Proposition 1 tells us that the non-cooperating firms contest with one firm that has $m$ products and spends the same effort on each product. Hence, we can consider profitability of cooperation for the two cases separately.

\subsection{High discriminatory power $(a>1)$}

Suppose $m<n$ firms cooperate in a contest with $a>1$. By Proposition 1 they spend effort on only one of their products. Without cooperation the set $M$ of firms received a payoff equal to $m \pi^{*}(n)$. With cooperation their payoff equals

$$
\pi^{*}(n-m+1)=\frac{B}{n-m+1}-\frac{a B(n-m)}{(n-m+1)^{2}} .
$$

\footnotetext{
${ }^{9}$ If $\mathrm{a}<1$, there is an advantagepof having a large number of products, because the total impact of a given budget $\mathbf{X}_{\mathrm{M}}=\mathrm{j} \in \mathrm{M} \mathbf{X}_{\mathrm{j}}$ is higher for a higher number $\mathrm{h}$ of products. However, the equilibrium reaction of the non-cooperative firms must also be taken into consideration. If the non-cooperating firms spend more effort in the equilibrium if $h$ is large, the cooperating firms' optimal choice of $\mathrm{h}$ becomes ambiguous. On the other hand, if $a>1$, the choice of $h$ becomes irrelevant. In that case all firms anticipate that the cooperating firms will concentrate all effort on one product. Hence, the choice of $h$ does not matter as any choice $\mathrm{h} \geq 1$ yields the same payoffs.
} 
Now let $g(n, m, a)$ be the function that measures the gain (or loss) of $m$ firms that merge in an industry composed of $n$ firms, i.e., $g(n, m, a)$ is given by

$$
\begin{aligned}
& g(n, m, a)=\pi^{*}(n-m+1)-m \pi^{*}(n) \\
& =\frac{B}{n-m+1}-\frac{a B(n-m)}{(n-m+1)^{2}}-m \frac{\mu^{B}}{n}-{\frac{a B(n-1)}{n^{2}}}^{\text {वी }}
\end{aligned}
$$

and has the following properties:

(i) For all $n \geq 2$ it holds that $g(n, 1, a)=0$. (If one firm is joined by no other in a merger, the profit doesn't change.)

(ii) For all $n \geq 2$ and for all $a>0$ it holds that $g(n, n, a)=\frac{B}{n} a(n-1)>0$. (Merger to monopoly is always profitable.)

(iii) For all $n \geq 2$ it holds that $\frac{\partial g(n, m, a)}{\partial m}=-\frac{B}{m}=\frac{B}{n^{3}}\left(2 a+n-2 a n+a n^{2}-n^{2}\right) \mathrm{S} 0$ iff $a \mathrm{~S} \frac{n(n-1)}{(n-1)^{2}+1} \quad \mathbf{i} \frac{n}{n-1}$ for $n \geq 2^{\Phi^{m}}$.

(iv) For all $n \geq 4$ and for all $a \in \stackrel{f}{0, \frac{n}{n-1}}^{\Phi}$ it holds that

$$
\frac{\partial^{2} g(n, m, a)}{\partial m^{2}}=2 B \frac{n-m+1-a(n-m-2)}{(n-m+1)^{4}}>0
$$

i.e., $g(n, m, a)$ is strictly convex (and also continuous) with regard to $m$.

With the help of properties $(i)-(i v)$ we can prove the following

Proposition 2 Let $\frac{n}{n-1}>a \geq 1$.

(A) If there are 3 firms then merger of two firms is profitable.

(B) For any number $n$ of firms, there is a critical discriminatory power $a_{0}(n)$ such that merger of $m \leq n-1$ is never profitable for all contests with $a \leq$ $a_{0}(n)$. 3

(C) Let $a \in 1, \frac{n(n-1)}{(n-1)^{2}+1}$ and $n \geq 4$. Then the following two statements hold true: If merger by a specified number of firms is not profitable for the merging firms, merger by a smaller number of firms is also not profitable. If merger by a specified number of firms is profitable for them, merger by a larger number of firms is also profitable.

(D) If $a \in \frac{n(n-1)}{(n-1)^{2}+1}, \frac{n}{n-1}$ then for any number $n \geq 4$ of firms merger of any number $m=2,3, \ldots, n$ of firms is profitable. 
Proof. For part (A) note that $g(3,2, a)=\frac{B}{36}(7 a-6)$. For part (B) note that $\lim _{a \rightarrow 0} g(n, m, a)=-\frac{(n-m)(m-1)}{n(n-m+1)} B<0$. The proof of part $(\mathrm{C})$ follows the lines of proof of result $D$ in Salant, Switzer, and Reynolds (1983): properties $(i)$ and (iii) imply that $g(n, m, a)$ becomes negative for small $m>1$ if $a<\frac{n(n-1)}{(n-1)^{2}+1}$. Note that $\frac{n(n-1)}{(n-1)^{2}+1}=\frac{(n-1)^{2}}{(n-1)^{2}+1} \frac{n}{n-1}$ with the first term on the right-hand side being smaller than 1 . According to property $(i v), g(n, m, a)$ is continuous and strictly convex with regard to $m$. Thus, because of property $(i i)$, there is a unique $y^{*}<n$ such that $g\left(n, y^{*}, a\right)=0$ and the result follows. Finally, for the proof of (D), it is straightforward to see that, in this case, properties $(i),(i i),(i i i)$ and $(i v)$ imply that $g(n, m, a)>0$ for all $m=2,3, \ldots, n$.

Intuitively, cooperation that makes firms in $M$ to concentrate their effort on one of their products has two effects. First, it increases total profit of the industry, because total contest effort is reduced with a reduction in the number of contestants. Second, the share of industry profit that goes to the cooperating group of firms is reduced. Proposition 2 shows that the profitability of cooperation depends on the discriminatory power of the contest and on whether the firms that take part in the merger constitute a large share in the total number of firms. If the discriminatory power is not too large, cooperation of many firms can be profitable whereas cooperation of few firms is not. However, if the discriminatory power is sufficiently high, merger - of any number of firms - is always profitable. ${ }^{10}$

\subsection{Low discriminatory power $(a<1)$}

Consider next the case in which cooperation does not reduce the number of products. The colluding firms take into account that an increase in contest effort on, say, the product of firm $i \in M$ reduces the market shares of all other firms' products, including the shares of the firms in $M$. This latter effect will be internalized, leading to a less aggressive effort choice of colluding firms. This, in turn, changes the contest behavior of all other firms. Using Proposition 1 for $a<1$, we obtain (reduced) payoff functions for the group

\footnotetext{
${ }^{10}$ We restricted attention to $a<\frac{n}{n-1}$ in order to concentrate on pure strategy equilibria. However, for $\mathrm{a} \rightarrow \infty$ and symmetry otherwise, with $\mathrm{m}<\mathrm{n}$, the contest is a symmetric fully discriminatory all-pay auction. It is known (see, e.g., Hillman and Riley (1989) and Baye, Kovenock and deVries (1996)) that all firms' payoff is zero in the (mixed strategy) equilibrium for this type of contest, whether firms cooperate or not.
} 
$M$ of colluding firms as

$$
\pi_{M}=\frac{m\left(\beta_{\mu}\right)^{a}}{m\left(x_{\mu}\right)^{a}+{ }_{k \in U}\left(x_{k}\right)^{a}} B-m x_{\mu}
$$

and for each non-cooperating firm $u \in U$ as

$$
\pi_{u}=\frac{\left(x_{\mathrm{p}}\right)^{a}}{m\left(x_{\mu}\right)^{a}+{ }_{j \in U}\left(x_{j}\right)^{a}} B-x_{u} .
$$

Maximization of (7) yields a first-order condition for the choice of $x_{\mu}$ which, after using symmetry for efforts of non-cooperating firms that is denoted as $x_{u}$, becomes

$$
a\left(x_{\mu}\right)^{a-1}(n-m)\left(x_{u}\right)^{a} B=\left[m\left(x_{\mu}\right)^{a}+(n-m)\left(x_{u}\right)^{a}\right]^{2},
$$

and maximization of (8) with respect to $x_{u}$ for $u \in U$ yields a first-order condition for the choice of non-cooperating firms which, after using symmetry, becomes

$$
a\left(x_{u}\right)^{a-1}\left((n-m-1)\left(x_{u}\right)^{a}+m\left(x_{\mu}\right)^{a}\right) B=\left[(n-m)\left(x_{u}\right)^{a}+m\left(x_{\mu}\right)^{a}\right]^{2} .
$$

This system of two equations determines $x_{\mu}$ and $x_{u}$, but is not analytically solvable, except for some special cases. This makes it impossible to compare the equilibrium profits $m \pi^{*}(n)$ of the $M$-group in the fully non-cooperative equilibrium with the equilibrium profits with collusion. However, we can solve three partial problems. First, we find

Proposition 3 At effort values of the fully non-cooperative equilibrium, noncooperating firms react to a marginal joint reduction in effort among colluding firms by an increase in their contest effort.

A proof is in the Appendix. If the firms in the colluding group $M$ uniformly choose an effort level that is slightly lower than the effort level $x^{*}(n)$ in the fully non-cooperative equilibrium, the firms outside this group anticipate this, and they choose higher efforts. As this holds for any size of the group $M$, Proposition 3 describes that efforts of the firms in $M$ and the efforts of the firms that do not cooperate are strategic substitutes locally at the fully non-cooperative equilibrium. This result contributes to the discussion on whether advertising redistributes market shares or increases the total market. The empirical study by Roberts and Samuelson (1989), for instance, finds "negative conjectural variations": A firm $i$ expects that other firms reduce their advertizing if $i$ increases its advertising effort on some of 
its brands. This negative slope of reaction functions is considered as counterintuitive if advertising is an activity that reallocates market shares in a market of given size. The negative slope is in line with advertising being a voluntary contribution to a collective good that increases the size of the whole market. Proposition 3 shows that the empirical finding by Roberts and Samuelson (1989) is also compatible with advertising as an activity that reallocates shares in a market of given size: reaction functions in contests can have negative slope in some range of the strategy space, and the slope is negative at the non-cooperative equilibrium. ${ }^{11}$

Proposition 4 A marginal joint reduction (increase) in effort among colluding firms which is observed by non-cooperating firms before they choose their effort increases their profit if the discriminatory power of the contest is smaller (bigger) than $\frac{n(m-1)}{m(n-2)}$.

A proof is in the appendix. Proposition 4 says that, if the colluding firms can choose effort as a Stackelberg leader, they can always do better than in the fully non-cooperative Nash equilibrium. To do this they choose effort that is smaller (larger) than the Nash equilibrium effort if $a$ is sufficiently small (large). Intuitively, the direct effect of cost savings from reduced effort within the colluding group outweighs the direct effect of reduced market share and the indirect effect of non-cooperating firms' changes in effort if the discriminatory power of the contest is sufficiently small. ${ }^{12}$

Let us return to simultaneous effort choices and consider the comparison of profits in the fully non-cooperative equilibrium and in the equilibrium with $m$ colluding firms. As pointed out above, for the general case with $a$, $n$ and $m$ arbitrary, the problem of comparing these payoffs is not tractable, because it is not possible to calculate closed-form solutions for the efforts in the equilibrium with collusion from (9) and (10). However, closed form solutions for efforts can be obtained for the case $m=n-1$. Note that this also includes the interesting case with $n=3$ and $m=2$. From (9) and

\footnotetext{
${ }^{11}$ Given that strategic complementarity or substitutability of effort choices is not a global property in contests, it is not surprising that the empirical results on strategic substitutability by Roberts and Samuelson (1989) are not uncontroversial (see, e.g., Seldon, Banerjee ad Boyd, 1993).

${ }^{12}$ Proposition 4 is of particular importance if collusion is interpreted in a broader sense, allowing for strategic arrangements among the merged firms. For instance, merger may lead to a holding company with a number of semi-independent firms, each choosing the contest effort for one brand. In this case, by way of appropriate incentive contracts for the CEO's of these single firms, the holding can implement any equilibrium choice of contest effort, in which case the result in Proposition 4 suggests that there is always a type of collusion that is profitable.
} 
(10) we obtain $x_{\mu}=\frac{a(n-1)^{\mathrm{a}} B}{\left((n-1)^{\mathrm{a}}+(n-1)\right)^{2}}$ and $x_{u}=(n-1) x_{\mu}$. Inserting in (7) and comparing this profit with $(n-1) \pi^{*}(n)$ yields

$$
\begin{gathered}
\pi_{M}-(n-1) \pi^{*}= \\
\frac{(n-1) B}{(n-1)+(n-1)^{\mathrm{a}}}-\frac{a(n-1)^{\mathrm{a}}(n-1) B}{\left((n-1)^{\mathrm{a}}+(n-1)\right)^{2}}-\frac{(n-1) B}{n}+\frac{a B(n-1)^{2}}{n^{2}}
\end{gathered}
$$

This expression is positive for all $a \in(0,1]$, as can be seen numerically from Figure 1 which depicts the profit gain from collusion for $B=1$, and we obtain from (11) $\lim _{n \rightarrow \infty}\left(\pi_{M}-(n-1) \pi^{*}\right)=a B$.

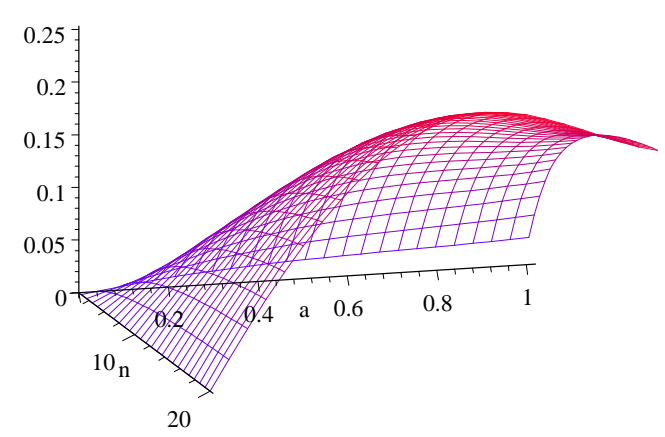

Figure 1. Profit gain of $m=n-1$ colluding firms

We summarize this result as

Proposition 5 Collusion of $n-1$ firms is always profitable for $a \in(0,1]$.

\section{Discussion and conclusions}

If we compare cooperation of a subgroup of firms in markets with promotional contests with cooperation in Bertrand or Cournot markets, we first observe that the cooperating group's choice of their number of products becomes important. Firms may or may not want to keep the number of brands they had prior to cooperation. We found that cooperating firms may reduce their number of products on which they spend sales effort. Furthermore, we found that the crucial determinants for this decision are the convexity properties of the contest success function. With high discriminatory power (increasing returns to scale) firms will concentrate their effort on one product (or brand), with low discriminatory power (decreasing returns) they will keep the whole range of products (or brands) and will equally spread out their efforts. 
The results on profitability of cooperation with or without a reduction of products are less straightforward than in Bertrand or Cournot competition. As is known from Deneckere and Davidson (1985), strategic complementarity as in the Bertrand competition case is sufficient for profitability. In contests, strategic complementarity or substitutability of contest efforts of different contestants is not a global property and changes across the strategy space. This fact makes it impossible to rely on the straightforward reasoning as used, for instance, in the Bertrand competition case. Nevertheless, we found that cooperation can be profitable in contests. Generally, cooperation tends to be profitable if the number of cooperating firms is comparatively large or if the total number of firms is comparatively small. Also, cooperation tends to be profitable if the discriminatory power in the contest is high.

A question which we did not address here is whether the cooperation of firms increases welfare. In the context considered here, cooperation which reduces the number of products (merger) reduces total contest effort. ${ }^{13}$ However, whether a reduction in total contest effort reduces or increases welfare depends on the nature of effort. For instance, if this effort is sales effort, the welfare effect depends on how effort affects consumers. Consumers may appreciate effort for its intrinsic value or for its information value. Also, effort may change customers' rents from consuming the product. Finally, effort can be pure waste or can have characteristics of a transfer.

\section{A ppendix}

Consider the effect of a symmetric marginal reduction in effort choices by the contestants in $M$ on their equilibrium profits. The first-order condition (10) determines how contestants in $U$ will react to an anticipated reduction in $x_{\mu}$. Define this function as

$$
x_{u}=\xi\left(x_{\mu}\right) \equiv \underset{x_{\mathrm{k}} \geq 0}{\arg \max }\left\{q_{k} B-x_{k} \mid x_{i}=x_{\mu} \forall i \in M \text { and } x_{j}=x_{u} \forall j \in U \backslash\{k\}\right\} .
$$

It is clear that such $x_{u}$ exists by standard fixed point arguments. $\xi$ is implicitly determined by (10). We call $\xi$ the symmetric reaction function of the non-cooperating firms for effort choices of the cooperating firms. At the fully non-cooperative equilibrium $x^{*}(n)$, the slope of the function $\xi$ is

\footnotetext{
${ }^{13}$ This is always the case in the symmetric case with merger. Whether collusion reduces total contest effort or not is less straightforward because of the negative reaction as in (13).
} 
obtained by total differentiation of (10) and equals

$$
\frac{d \xi(x) \overline{-}_{x=x^{*}}}{d x}=-\frac{a m(n-2)}{(n-a m)(n-1)+a m} .
$$

The slope of the reaction function $\xi$ at the fully non-cooperative Nash equilibrium as in (13) is strictly negative for all $n \geq 3$ and $m \leq n-1$. To see this, note that $a \leq \frac{n}{n-1}$. This confirms Proposition 3. $\mathbb{x}$

Consider now Proposition 4. As $\frac{\partial \pi_{\mathrm{k}}}{\partial x_{\mathrm{k}}}=0$ and $\frac{\partial \pi_{\mathrm{i}}}{\partial x_{\mathrm{k}}}=-\frac{1}{n-1}$ for $i \neq k$ at the fully non-cooperative Nash equilibrium with efforts as in (3), the profit increase of each firm in the merging group $M$ from a joint reduction in their contest effort $x$ starting in $\left(x^{*}, x^{*}\right)$ equals

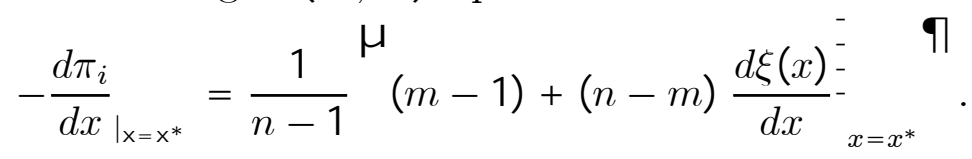

This condition resembles condition (5) in Gaudet and Salant (1991) who consider Cournot competition. Inserting (13) yields

$$
-\left.\frac{d \pi_{i}}{d x}\right|_{\mathrm{x}=\mathrm{x}^{*}}>0 \text { iff } a<\frac{n(m-1)}{m(n-2)}
$$

which confirms Proposition 4. $\mathfrak{x}$

\section{R eferences}

[1] Bagwell, Kyle, and Robert W. Staiger, 1997, Strategic export subsidies and reciprocal trade agreements, the natural monopoly case, Japan and the World Economy, 9, 491-510.

[2] Barros, Petro Pita and Lars Sørgard, 2000, Mergers in an advertisingintensive industry, mimeo.

[3] Baye, Michael R., Dan Kovenock, and Casper G. deVries, 1998, A general linear model of contests, mimeo.

[4] Baye, Michael R., Dan Kovenock, and Casper G. deVries, 1994, The solution to the Tullock rent-seeking game when $\mathrm{R}$ is greater than 2 : mixed-strategy equilibria and mean dissipation rates, Public Choice, 81, 363-380.

[5] Baye, Michael R., Dan Kovenock, and Casper G. deVries, 1996, The allpay auction with complete information, Economic Theory, 8, 291-305. 
[6] Besen, Stanley M., and Joseph Farrell, 1994, Choosing how to compete: strategies and tactics in standardization, Journal of Economic Perspectives, 8, 117-131.

[7] Breyer, Friedrich, and Peter Zweifel, 1999, Gesundheitsökonomie, Springer, Heidelberg.

[8] Deneckere, Raymond, and Carl Davidson, 1985, Incentives to form coalitions with Bertrand competition, Rand Journal of Economics, 16, 473486.

[9] Dijkstra, Bouwe R., 1999, The Political Economy of Environmental Policy, A Public Choice Approach to Market Instruments, Edward Elgar, Cheltenham, UK.

[10] Farrell, Joseph, and Carl Shapiro (1990): Horizontal mergers: an equilibrium analysis, American Economic Review, 80, 107-126.

[11] Fullerton, Richard L., and R. Preston McAfee, 1999, Auctioning entry into tournaments, Journal of Political Economy, 107, 573-605.

[12] Gaudet, Gerard, and Stephen W. Salant, 1991, Increasing the profits of a subset of firms in oligopoly models with strategic substitutes, American Economic Review, 81, 658-665.

[13] Harsanyi, John, 1977, Rational Behavior and Bargaining Equilibrium in Games and Social Situations, Cambridge, Cambridge University Press.

[14] Hillman, Arye, and John G. Riley, 1989, Politically contestable rents and transfers, Economics and Politics, 1, 17-40.

[15] Konrad, Kai A., 2000, Trade contests, Journal of International Economics, 51(2), 317-334.

[16] Nguyen, Dung, 1987, Advertising, random sales response, and brand competition: some theoretical and econometric implications, Journal of Business, 60(2), 259-279.

[17] Nitzan, Shmuel, 1994, Modelling rent-seeking contests, European Journal of Political Economy, 10, 41-60.

[18] Rees, Ray, and Ekkehard Kessner, 1999, European insurance markets, regulation and efficiency, Economic Policy, 29, 363-397. 
[19] Roberts, Mark J. and Larry Samuelson, 1988, An empirical analysis of dynamic, nonprice competition in an oligopolistic industry, Rand Journal of Economics, 19, 200-220.

[20] Salant, Stephen W., Sheldon Switzer, and Robert J. Reynolds, 1983, Losses from horizontal merger: the effects of an exogenous change in industry structure on Cournot-Nash equilibrium, Quarterly Journal of Economics, 98, 185-199

[21] Scherer, F.M., 2000, The pharmaceutical industry, in: A.J. Culyer and J.P. Newhouse, Handbook of Health Economics, Vol. 1B, 1297-1336.

[22] Schmalensee, Richard, 1976, A model of promotional competition in oligopoly, Review of Economic Studies, 43, 493-507.

[23] Schmalensee, Richard, 1992, Sunk costs and market structure, a review article, Journal of Industrial Economics, 40, 125-134.

[24] Seldon, Barry J., 1993, Advertising conjectures and the nature of advertising competition in oligopoly, Managerial and Decision Economics, $14,489-498$.

[25] Skaperdas, Stergios, 1996, Contest success functions, Economic Theory, 7, 283-290.

[26] Thomas, Lacy Glenn, 1989, Advertizing in consumer goods industries: durability, economies of scale, and heterogeneity, Journal of Law and Economics, 32, 163-193.

[27] Tullock, Gordon, 1980, Efficient rent seeking, in: J.M. Buchanan, R.D. Tollison and G. Tullock, eds., Toward a Theory of Rent-seeking Society (Texas A\&M University Press, College Station) 97-112. 